\title{
High Temperature Dielectric Properties of Iron- and Zinc-Bearing Products during Carbothermic Reduction by Microwave Heating
}

\author{
Beatriz García-Baños ${ }^{1, *(\mathbb{C})}$, Jose M. Catalá-Civera ${ }^{1}$, Juan R. Sánchez ${ }^{1}{ }^{\circledR}$, Laura Navarrete ${ }^{2}$, \\ Angel M. López-Buendía ${ }^{3}$ and Lukas Schmidt ${ }^{4}$ \\ 1 ITACA Institute, Universitat Politècnica de València, Camino de Vera s/n, 46022 Valencia, Spain; \\ jmcatala@dcom.upv.es (J.M.C.-C.); jrsanchez@itaca.upv.es (J.R.S.) \\ 2 Instituto de Tecnología Química, Universitat Politècnica de València-Consejo Superior de Investigaciones \\ Científicas, Camino de Vera s/n, 46022 Valencia, Spain; launaal@itq.upv.es \\ 3 Innovation Centre, INNCEINNMAT.SL, C/Catedrático Agustín Escardino, 9, 46980 Valencia, Spain; \\ angel.lopez@ceinnmat.com \\ 4 Research Area Raw Materials \& Recycling, K1-MET, Stahlstraße 14, 4020 Linz, Austria; \\ lukas.schmidt@k1-met.com \\ * Correspondence: beagarba@upvnet.upv.es; Tel.: +34-96-3879742
}

Received: 30 April 2020; Accepted: 22 May 2020; Published: 25 May 2020

\begin{abstract}
In this work, the carbothermic reduction of iron- and zinc-bearing products is studied through in situ microwave heating, dielectric properties monitoring, and mass spectrometry up to high temperatures $\left(1000^{\circ} \mathrm{C}\right)$. The results are correlated to the information provided by conventional analysis techniques such as differential scanning calorimetry (DSC) and thermogravimetry (TG). This combination allows a detailed study of seven different process stages with an accurate determination of the reaction temperatures, providing new evidence about the particular conditions of this microwave-driven reduction process. The presented results suggest that molecular vibrations imposed by the microwave field are presumably the reason for reactions taking place at lower temperatures than those observed in the conventional process. This work also explores the influence of other parameters, such as the apparent density or the amount of carbonaceous material, on the resulting dielectric properties, providing useful information for the development of a potential microwave industrial application in the metallurgy field.
\end{abstract}

Keywords: microwave heating; dielectric properties; carbothermic reduction; iron oxides; zinc ferrite; mass spectrometry; iron and zinc recovery

\section{Introduction}

Microwave processing has emerged as a versatile form of energy with many advantages over more conventional heating technologies, including chemical reaction enhancement, shorter time cycles, substantial energy savings, and higher quality of the final product. In recent years, the potential of microwave energy in metallurgy processes has been described in the literature with numerous published papers [1-3]. This is an attractive interdisciplinary field seeking ecofriendly solutions for critical processes required for economic growth. One of these processes is the production of steel, given the high demand of fossil energy and significant $\mathrm{CO}_{2}$ emissions. In Europe, 59.6\% of the total European steel $(168.5 \mathrm{Mt})$ is produced via the basic oxygen furnace (BOF) route with hot metal from blast furnaces (BF) [4]. The rest (40.4\%) comes from electric arc furnaces (EAF). Residues such as the BOF and BF dust and sludge can be recycled, which represents clear economic and environmental advantages. In the recycling process, the residues (mixture of iron oxides) are mixed with a carbonaceous material 
and heated at high temperatures, causing their carbothermic reduction to separate and recover metals such as iron and zinc.

This reduction process is well-known in the pyrometallurgical industry which has made use of different technologies including several attempts with microwave heating [1-3,5-13]. Recent studies have shown microwave technology as a very promising option for the carbothermic reduction and the decrease of the $\mathrm{CO}_{2}$ emissions in the steel production chain, since iron and steelmaking process residues have good microwave absorbing properties owing to their carbon and iron oxides content. Some of the reported advantages are the volumetric and fast heating of the mixture $[2,3,5,7]$, enhanced reaction diffusion kinetics $[1,3,6]$, and a lower demand of carbon needed $[1,10]$ for the reduction process. The possibility to employ wastes with high carbon content such as biochar has been also pointed out by other authors [11,12]. Since the demands on the quality of the carbon used in the microwave process are rather low, blast furnace sludge (whose high zinc content due to enrichment may pose a problem for its reuse in the conventional process) is selected in this study as carbonaceous material with the additional advantage of a further $\mathrm{CO}_{2}$ emission decrease.

In spite of these promising results, it is also recognized that there are still difficulties hindering the extensive application of microwave technology in the metallurgy field $[1,2,8]$. Many different physical phenomena are involved in the microwave processing of materials, and the specific causes behind unusual enhancements in reaction and sintering kinetics are seldom understood. In the particular case of iron ores, the multiscale nature of interacting components and the structural heterogeneities cause significant challenges for understanding their electromagnetic behavior. The ability of a material to interact with microwave energy is related to the material's dielectric properties (dielectric constant and loss factor). Thus, the investigation of the dielectric properties of materials involved in the carbothermic reduction of iron oxides and their evolution with temperature can provide the information to identify the dominant factors that lead the process in order to exploit the benefits that microwave technology can offer. Unfortunately, high temperature dielectric data are scarce in the literature for pure compounds and in particular for complex mixtures such as the ones considered here.

Several techniques have been reported to measure the dielectric properties of iron ores [14], zinc oxide [6,15], zinc ferrite [6,15,16] or related materials such as electric arc furnace dusts $[10-12,15,17]$. The most widely used technique is the open-ended coaxial probe, because it allows convenient non-invasive dielectric measurements by contacting just one face of the material. However, for granular or powder materials, this technique is prone to measurement errors due to uneven small air gaps or local variations of sample compaction in the zone closest to the probe surface, which is the most sensitive part of the probe [18].

Previous attempts to measure dielectric properties at different temperatures during the carbothermic reduction process have been made employing conventional heating furnaces [6,10-12,14-17]. The samples are placed in the furnace and heated to the desired temperature, then moved quickly to the measurement fixture. This technique presents several disadvantages: (i) the sequence of reactions followed under conventional heating may not be representative for the microwave process; (ii) the sample unavoidably cools down during the measurement, especially at high temperatures $\left(>500{ }^{\circ} \mathrm{C}\right)$ [19]. These problems increase the measurement uncertainty and make this technique inadequate if the material undergoes fast or irreversible changes at certain temperatures, because the change of properties can be lost during sample movement, or measured temperatures can mislead the interpretation of the sequence of reactions [19,20].

Thus, the study of this complex process requires advanced microwave equipment being able to provide in situ dielectric measurements to ensure that results are providing real and accurate information about the different reaction stages occurring under microwave field, independently of how fast they evolve. In contrast to previously reported studies, a recently developed dual-mode microwave system [21] is employed in this work, both to heat and measure the dielectric properties of the mixtures during the carbothermic reduction. The reactions are microwave-driven as in the intended application, and dielectric properties of the samples are continuously monitored in the same heating cell. To provide further in-situ information about the different reaction stages, a mass spectrometer is integrated for continuous 
analysis of the gases released during the process. This combination of in situ microwave heating, dielectric characterization and mass spectrometry up to high temperatures $\left(1000^{\circ} \mathrm{C}\right)$ represents a novel configuration for the study of carbothermic reduction of iron- and zinc-bearing mixtures providing useful information for a potential microwave industrial application of this process.

In order to better understand the kinetics of the different materials reactions under microwave heating, this work also explores the relation of dielectric properties with other analytic techniques such as differential scanning calorimetry (DSC) and thermogravimetry (TG). This combination of techniques allows the precise sequence of reactions to be clearly detected in-situ. Critical points during microwave reduction can be identified at their corresponding temperatures, providing new information about the particular conditions of microwave reduction processes. In addition, the influence of other parameters such as the density or the amount of carbonaceous material on the resulting dielectric properties is also measured, in order to broaden our knowledge about this process in particular and to help the understanding of the heating mechanisms behind microwave metallurgy in general.

\section{Materials and Methods}

\subsection{Samples}

The samples employed in this study were composed by mixtures of steel work residues (BOF dusts and sludge) rich in zinc and iron, supplied by DK Recycling und Roheisen GmbH (Duisburg, Germany).

Blast furnace (BF) sludge having a considerable amount of carbon (as metallurgical coke) was added to the mixture as the necessary carbonaceous material to promote the carbothermic reduction. The amount of BF sludge was calculated according to the required carbon input, based on the amount of combined oxygen in the iron oxides. The sample with a stoichiometric carbon to oxygen ratio $(\mathrm{C} / \mathrm{O}=100 \%)$ was considered as the reference case, but samples with $\mathrm{C} / \mathrm{O}$ ratios $\mathrm{C} / \mathrm{O}=50 \%, 80 \%$ and $120 \%$ were also investigated with dielectric measurements. Tables 1 and 2 show the chemical and mineralogical analyses of reference sample $(\mathrm{C} / \mathrm{O}=100 \%)$.

The as-received samples were inhomogeneous. Blast furnace sludge was processed in a jaw crusher before mixing and afterwards the samples were homogenized by an intensive Eirich Mixer (Gustav Eirich GmbH \& Co KG, Hardheim, Germany) and dried. The fraction below $2 \mathrm{~mm}$ was sieved for subsequent analyses. A dry particle size measurement was carried out with a Camsizer (Retsch $\mathrm{GmbH}$, Haan, Germany) Free-fall mode. The mean particle size was $0.62 \mathrm{~mm}$ and the ratio $X(90 \%) / X(10 \%)$ was 5.52 (where $X$ is the diameter of the particle and $X(Y \%)$ means that $Y \%$ of all particles have a diameter below certain value).

Table 1. Chemical composition of reference sample $(\mathrm{C} / \mathrm{O}=100 \%)$.

\begin{tabular}{cccc}
\hline Compound & wt $\%$ & Compound & wt $\%$ \\
\hline $\mathrm{Fe}_{\text {tot }}$ * & 47.32 & $\mathrm{Mn}$ & 0.73 \\
$\mathrm{C}$ & 13.70 & $\mathrm{~S}$ & 0.73 \\
$\mathrm{Zn}$ & 13.41 & $\mathrm{Rb}$ & 0.63 \\
$\mathrm{SiO}_{2}$ & 12.37 & $\mathrm{~K} 2 \mathrm{O}$ & 0.59 \\
$\mathrm{CaO}$ & 4.53 & $\mathrm{~Pb}$ & 0.53 \\
$\mathrm{MgO}$ & 3.18 & $\mathrm{NaO}$ & 0.16 \\
$\mathrm{Al}_{2} \mathrm{O}_{3}$ & 2.06 & $\mathrm{LOI}$ & n.a. $* *$ \\
\hline
\end{tabular}

${ }^{*} \mathrm{Fe}_{\text {tot: }}$ Iron content in all iron oxides as well as small amount in metallic form; ** Not available. 
Table 2. Mineralogical analysis of reference sample (C/O = 100\%).

\begin{tabular}{ccc}
\hline Mineral Phase & Formula & Abundance \\
\hline Franklinite & $\mathrm{ZnFe}_{2} \mathrm{O}_{4}$ & $\mathrm{xxxx}$ \\
Magnetite & $\mathrm{Fe}_{3} \mathrm{O}_{4}$ & $\mathrm{xxx}$ \\
Ca-Zn Hydroxide Hydrate & $\mathrm{Ca}\left(\mathrm{Zn}_{2}(\mathrm{OH})_{6}\right)\left(\mathrm{H}_{2} \mathrm{O}\right)_{2}$ & $\mathrm{xxx}$ \\
Quartz & $\mathrm{SiO}_{2}$ & $\mathrm{xxx}$ \\
Hematite & $\mathrm{Fe}_{2} \mathrm{O}_{3}$ & $\mathrm{xxx}$ \\
Calcite & $\mathrm{CaCO}_{3}$ & $\mathrm{xx}$ \\
Carbon & $\mathrm{C}$ & $\mathrm{xx}$ \\
Wüstite & $\mathrm{FeO}$ & $\mathrm{x}$ \\
Metallic Iron & $\mathrm{Fe}$ & $\mathrm{x}$ \\
Zincite & $\mathrm{ZnO}$ & $\mathrm{x}$ \\
\hline
\end{tabular}

${ }^{1} \mathrm{x}$ indicates the abundance ( $\mathrm{xxxx}=$ major, $\mathrm{x}=$ traces $)$.

\subsection{Dielectric Characterization as a Function of Temperature}

The ability of a material to interact with microwave energy is related to the material's dielectric properties (dielectric constant and loss factor), and they depend on many factors such as material composition, temperature, density or frequency. The dielectric properties are defined by the complex number

$$
\varepsilon_{r}=\varepsilon_{r}^{\prime}-j \varepsilon_{r}^{\prime \prime}
$$

where $j$ is the imaginary unit, the real part $\varepsilon_{r}^{\prime}$ is the relative dielectric constant, which indicates the ability of the material to store energy from an external electric field, and the imaginary part $\varepsilon_{r}^{\prime \prime}$ is the loss factor, which indicates the ability of the material to transform this energy into heat.

There are other related parameters of interest such as the penetration depth $\left(D_{p}\right)$, which gives an estimation of the appropriate size of the material that can be processed. It is defined as the distance at which power density is reduced to $1 / e$ of its value at the surface of the material, which can be calculated as:

$$
D_{p}=\frac{c}{2 \pi f \sqrt{2 \varepsilon_{r}^{\prime}\left(\sqrt{1+\left(\frac{\varepsilon_{r}^{\prime \prime}}{\varepsilon_{r}^{\prime}}\right)^{2}}-1\right)}}
$$

where $c$ is the speed of light in free space, and $f$ is the frequency.

Figure 1 shows the microwave dual mode system employed for the carbothermic reduction of samples with in situ determination of dielectric properties as a function of sample temperature. It is based on a cylindrical cavity designed to irradiate microwave power near the ISM (Industrial, Scientific and Medical applications) standard frequency of $2.45 \mathrm{GHz}$. The heating mode $\left(\mathrm{TE}_{111}\right)$ presents a zone of maximum electric field in the cavity center, where the material is placed. The size of the sample (10 $\mathrm{mm}$ diameter, $15 \mathrm{~mm}$ height) ensures uniform electric field distribution inside the sample, with a maximum incident power of $150 \mathrm{~W}$. The measuring mode $\left(\mathrm{TM}_{010}\right)$ is uniform in height and a cross-coupling filter avoids any interference with the heating mode. A detailed description of the system can be found in [21].

In order to measure the dielectric properties during the carbothermic reduction process, the samples are placed in a quartz holder and inserted in the microwave cavity through an insertion hole. The heating rate is fixed to $15{ }^{\circ} \mathrm{C} / \mathrm{min}$ under continuous nitrogen flow. An IR pyrometer (OPTRIS GmbH, Berlin, Germany) measures the surface temperature of the quartz holder from the lateral through an inspection hole in the cavity wall. A thorough calibration procedure is applied to obtain the bulk sample temperature from surface temperature measurements [20]. 


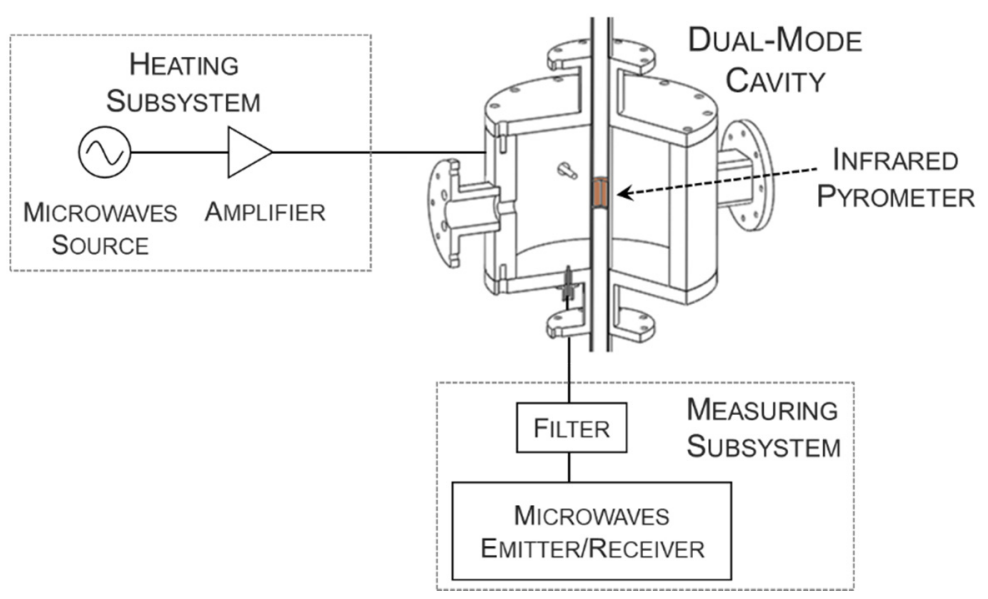

Figure 1. Schematic view of experimental set-up with the microwave dual system for heating and measuring the dielectric properties of samples during the carbothermic reduction process. The sample is placed inside a quartz holder and located in the center of the cylindrical microwave cavity.

The determination of the sample dielectric properties is based on the cavity perturbation method (CPM), from the measurement of the cavity resonant frequency and quality factor. The presence of the sample modifies the resonance properties of the microwave cavity and these changes are measured to determine the dielectric properties. An improved version of the CPM method described in [21] provides an accuracy of 3\% for the measurement of the dielectric constant and 10\% for the loss factor.

In this work, only the contribution of electric field and the material dielectric properties were considered. The contribution of magnetic heating was not considered for two reasons. The first is that the sample is placed in a position with maximum electric field and minimum magnetic field (see [21] for a detailed description of the electromagnetic field distribution of the heating mode). The second reason is that, according to previous studies [11], the contribution of magnetic loss would only play a role at temperatures below the Curie temperature (approx. $500{ }^{\circ} \mathrm{C}$ ), being negligible when the material temperature increases further.

\subsection{Dielectric Characterization as a Function of Density}

In the case of powder or granular materials, there is a strong influence of the apparent density on the measured dielectric properties, especially if the dielectric properties of the sample differ from those of the air (as it is the case with iron oxides). It is thus necessary to quantify the variation in the dielectric properties that can be expected when the samples are compacted to different extent.

These measurements were carried out with microwave equipment specifically designed for very accurate determination of dielectric properties of particulate materials at room temperature. The samples were placed inside a standard $1 \mathrm{~mL}$ pyrex tube and the equipment reported in [22] was used. It provides an accuracy of approx. $1 \%$ in dielectric constant and $2-5 \%$ in the loss factor.

\subsection{Thermogravimetry (TG) and Differential Scanning Calorimetry (DSC)}

Differential scanning calorimetry (DSC) and thermogravimetry (TG) were selected to study the thermal behavior of samples under conventional heating. In general, TG gives information about the mass loss of the sample as a function of temperature, whereas DSC is employed to detect thermal reactions. These thermal analyses of the iron oxides were performed with a NETZSCH STA 449F5 (NETZSCH, Selb, Germany) under nitrogen atmosphere with a flow of $50 \mathrm{~mL} / \mathrm{min}$. Approximately $40 \mathrm{mg}$ of sample were placed in a platinum crucible on an alumina pan at a heating rate of $20^{\circ} \mathrm{C} / \mathrm{min}$, from $35^{\circ} \mathrm{C}$ to $1000{ }^{\circ} \mathrm{C}$. 


\subsection{Mass Spectrometry}

A mass spectrometer (Pfeiffer Vacuum Omni Star GSD 320 O1, Pfeiffer Vacuum GmbH, Asslar, Germany) was placed at the reactor output for continuous monitoring of the gases released during the microwave process. The mass spectrometer consists of two detectors, namely a Faraday and Channeltron (electron multiplier), and is able to detect low concentrations ( $>100 \mathrm{ppb}$ ). The experiments were carried out with a constant flow of $50 \mathrm{~mL} / \mathrm{min}$ of dry nitrogen. In order to discern between the different signals associated with $\mathrm{CO}, \mathrm{CO}_{2}, \mathrm{H}_{2} \mathrm{O}$ and $\mathrm{N}_{2}$, the main and secondary ionized masses of each compound were followed during the whole experiment.

\subsection{X-Ray Diffraction}

Crystalline phase identification was performed by X-ray diffractions (XRD) in a Bruker D8 X-ray diffractometer with a Lynx eye detector (Bruker Española SA, Madrid, Spain). Random oriented powder sample ( $<50 \mu \mathrm{m}$ size) was analyzed working at $40 \mathrm{kV}$ and $30 \mathrm{~mA}$, with $\mathrm{CuK} \alpha$ radiation and graphite monochromator. Data were collected in the range of $10-90^{\circ}(2 \theta)$, with a scan step of $0.02^{\circ}$ and a counting time of $63.4 \mathrm{~s}$ per step. Crystalline phases identification was made with the software Match! Version 3.10 (Crystal Impact, Bonn, Germany).

\section{Results and Discussion}

\subsection{Dielectric Properties, Thermal Analysis and Mass Spectrometry during Carbothermic Reduction}

Figure 2 shows the dielectric constant and loss factor of reference sample $(C / O=100 \%)$ as a function of temperature during microwave heating process, together with the results from TG and DSC measurements. TG and DSC rely on conventional heating and thus process stages may not match with those observed under microwave heating. However, they provide useful information about the reactions taking place in the approximate temperature ranges, and are depicted in the same figure for comparison purposes.

In general terms, dielectric properties increase with temperature, with some variations and some peaks at certain temperatures that can be attributed to the different stages in the reduction process. These stages have been identified and illustrated in Figure 2 through the combination of the different measurement techniques and careful analysis of phase equilibrium diagrams. Due to the interest of this carbo-reduction process, these diagrams can be easily found in the literature, and the reader is referred to [9-12] as a few examples. The different identified stages can be explained as follows.

At low temperatures (below $330^{\circ} \mathrm{C}$, stage 1), the increase in dielectric properties is slow with some local maxima in the dielectric constant from 100 to $300{ }^{\circ} \mathrm{C}$, mainly due to free water vaporization and dehydration of coke. According to the composition (Table 2), the sample contains calcium-zinc hydroxide-hydrate that dehydrates at these temperatures as follows:

$$
\mathrm{Ca}\left(\mathrm{Zn}_{2}(\mathrm{OH})_{6}\right)\left(\mathrm{H}_{2} \mathrm{O}\right)_{2}=\mathrm{Ca}\left(\mathrm{Zn}_{2}(\mathrm{OH})_{6}\right)+2 \mathrm{H}_{2} \mathrm{O}
$$

During evaporation, water exhibits a relevant increment on the mobilization and polarizability capacity, with the consequent increase on dielectric properties. The dielectric properties due to water evaporation are changing dynamically and they are directly proportional to the evaporation mass speed and inversely proportional to water loss. This change in dielectric properties can be correlated to the DSC peak around $181^{\circ} \mathrm{C}$ with its corresponding mass loss in the TG at this temperature.

Around $428^{\circ} \mathrm{C}$ (stage 2), DSC measurement shows a reaction related to dehydroxylation of calcium hydroxide [15] with a second small mass loss in the TG, following the reaction equation:

$$
\mathrm{Ca}\left(\mathrm{Zn}_{2}(\mathrm{OH})_{6}\right)=\mathrm{CaO}+2 \mathrm{ZnO}+3 \mathrm{H}_{2} \mathrm{O}
$$




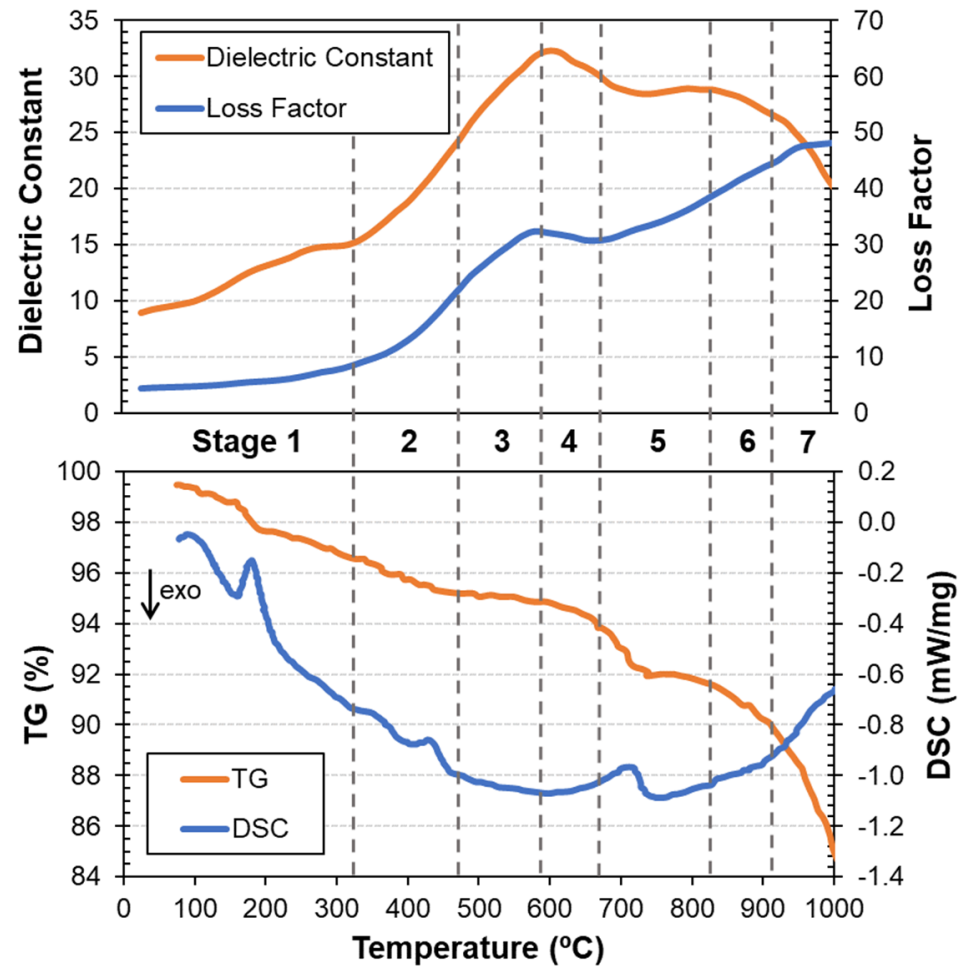

Figure 2. Dielectric properties and thermal analyses (thermogravimetry (TG) and differential scanning calorimetry (DSC)) of reference sample $(\mathrm{C} / \mathrm{O}=100 \%)$ as a function of temperature.

The calcium hydroxide exhibits low dielectric properties, showing the crystalline and linked $\mathrm{OH}$ molecules forming the HO-Ca-OH structure. However, during dehydroxylation, $\mathrm{OH}$ is sublimated to very polar $\mathrm{OH}$ - molecules that produce a very high and fast dielectric properties increase. During $\mathrm{OH}$ depletion from the structure, the crystal structure still shows higher polarity with respect to the initial value, due to uncompensated charges until the recrystallization generates a new structure. Thus, dehydroxylation leads to a substantial increase both in the dielectric constant and loss factor. In this stage, also the decomposition of coke starts, releasing light volatile organic compounds (VOCs), which contributes to the mass loss detected by the TG.

When the sample is close to $500{ }^{\circ} \mathrm{C}$ (stage 3), the loss factor presents a change in the increasing rate indicating that a new reaction begins. According to previous studies [10], decomposition of zinc ferrite in the presence of carbon can take place from $500{ }^{\circ} \mathrm{C}$ as follows:

$$
\begin{gathered}
\mathrm{C}+\mathrm{ZnFe}_{2} \mathrm{O}_{4}=\mathrm{ZnO}+2 \mathrm{FeO}+\mathrm{CO}(\mathrm{g}) \\
\mathrm{CO}(\mathrm{g})+\mathrm{ZnFe}_{2} \mathrm{O}_{4}=\mathrm{ZnO}+2 \mathrm{FeO}+\mathrm{CO}_{2}(\mathrm{~g})
\end{gathered}
$$

where Equations (5) and (6) are known as direct and indirect reduction reactions, respectively. In the presence of the carbonaceous material, these reactions would lead to $\mathrm{CO}$ and $\mathrm{CO}_{2}$ emissions. Transformation of magnetite directly to metallic iron is also likely to occur in this stage (from $500^{\circ} \mathrm{C}$ [11]) in the presence of $\mathrm{CO}$, emitting $\mathrm{CO}_{2}$ :

$$
\mathrm{Fe}_{3} \mathrm{O}_{4}+4 \mathrm{CO}(\mathrm{g})=3 \mathrm{Fe}+4 \mathrm{CO}_{2}(\mathrm{~g})
$$

The decomposition of coke is also expected at these temperatures. The off-gas analysis (Figure 3) shows that $\mathrm{CO}$ and $\mathrm{CO}_{2}$ emissions start during this stage. 


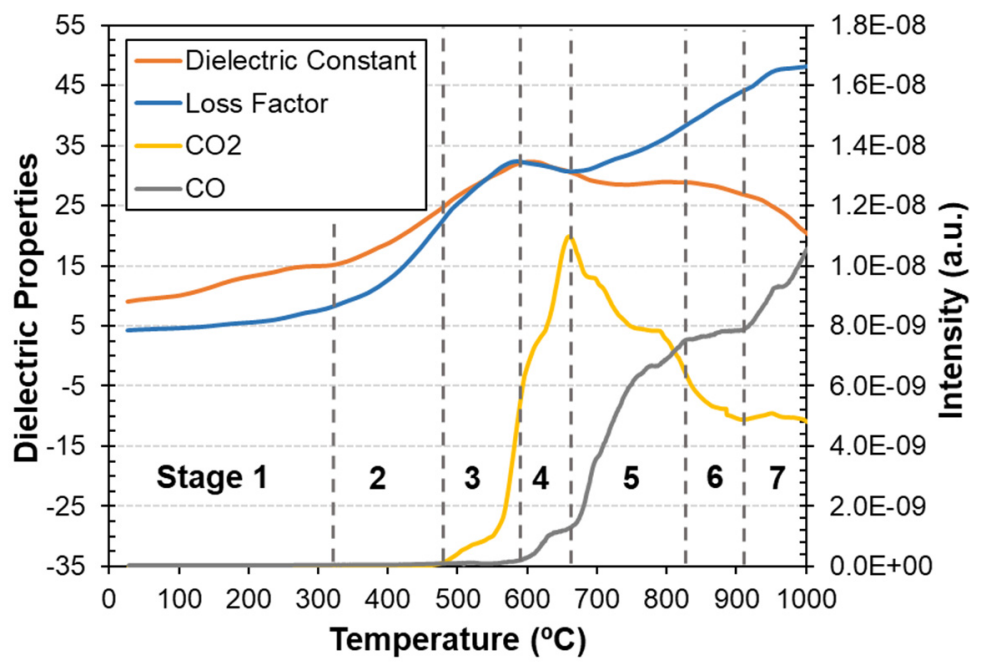

Figure 3. Dielectric properties and mass spectrometry ( $\mathrm{CO}$ and $\mathrm{CO}_{2}$ gases) of reference sample $(\mathrm{C} / \mathrm{O}=100 \%)$ as a function of temperature.

When the temperature of the sample is close to $600{ }^{\circ} \mathrm{C}$ (stage 4), there is a clear change of tendency in the dielectric properties, which start to decrease. This indicates that other reactions initiate in this temperature range. Since the dielectric properties decrease, this change can be attributed to the formation of wüstite $(\mathrm{FeO})$ by the reduction of magnetite as follows:

$$
\mathrm{Fe}_{3} \mathrm{O}_{4}+\mathrm{CO}(\mathrm{g})=3 \mathrm{FeO}+\mathrm{CO}_{2}(\mathrm{~g})
$$

leading to an increase in the amount of emitted $\mathrm{CO}_{2}$, as can be seen in the mass spectra (Figure 3). The reduction of magnetite to wüstite during this stage agrees to previous studies which indicate that wüstite presents lower dielectric properties than magnetite [7]. At this point, it should be noted that, according to the conventional Baur-Glaessner diagram (see [23]), magnetite cannot be reduced to wüstite below $647^{\circ} \mathrm{C}$, if the Boudouard reaction is also considered:

$$
\mathrm{C}+\mathrm{CO}_{2}(\mathrm{~g}) \leftrightarrow 2 \mathrm{CO}(\mathrm{g})
$$

However, several studies found evidence of magnetite reduction at lower temperatures (from $\left.580{ }^{\circ} \mathrm{C}\right)$, when microwave energy is employed $[1,6,7]$. Although the exact causes are not clear, it seems that molecular vibrations at microwave frequencies reduce the energy required to cut links between them, improving the kinetic condition of the reaction [8,24]. In fact, oxide reduction at lower temperatures is considered one of the advantages of microwave utilization in this process.

During this stage, the levels of $\mathrm{CO}$ and $\mathrm{CO}_{2}$ change due to the different reactions taking place combined with the Boudouard reaction (9) that defines different equilibrium ratios between both gases depending on the temperature, as $\mathrm{CO}_{2}$ and $\mathrm{C}$ tend to convert into $\mathrm{CO}$ at temperatures above $700{ }^{\circ} \mathrm{C}$. It should be noted that $\mathrm{CO}$ production could be increased if oxygen is supplied in the reactor, as in real industry conditions.

From about $680{ }^{\circ} \mathrm{C}$ (stage 5), other reaction take place producing a remarkable increase of the sample loss factor. From this temperature, wüstite can be further reduced to metallic iron in the reducing atmosphere, whereas $\mathrm{CO}_{2}$ is generated according to the following reaction:

$$
\mathrm{FeO}+\mathrm{CO}(\mathrm{g})=\mathrm{Fe}+\mathrm{CO}_{2}(\mathrm{~g})
$$

Analogously to the case of magnetite reduction, the observed temperatures for wüstite reduction under microwave heating are below the expected temperature $\left(698^{\circ} \mathrm{C}\right)$ from the Baur-Glaessner 
diagram [23]. This fact was also observed in previous studies [10,11], where wüstite was reduced to metallic iron from $678{ }^{\circ} \mathrm{C}-680^{\circ} \mathrm{C}$.

In addition, the TG shows a mass loss at $711^{\circ} \mathrm{C}$, together with an endothermic peak in the DSC curve, which contrasts with the exothermic iron oxides reduction. This peak can be attributed to the thermal decomposition of calcium carbonate (see calcite in Table 2) with $\mathrm{CO}_{2}$ release at this temperature [15]. The increase of loss factor values in this stage would then be associated to this reaction together with the newly generated metallic iron phase, which would result in a gradually increasing electronic conduction and higher conductive losses [11].

In stage 5, the emitted $\mathrm{CO}_{2}$ contributes to the production of higher levels of $\mathrm{CO}$ (Figure 3) due to the new equilibrium of the Boudouard reaction at these temperatures.

At $839^{\circ} \mathrm{C}$, stage 6 starts with the reduction of $\mathrm{ZnO}$ to metallic $\mathrm{Zn}$ (liquid) according to the reaction:

$$
\mathrm{ZnO}+\mathrm{CO}(\mathrm{g})=\mathrm{Zn}(\mathrm{l})+\mathrm{CO}_{2}(\mathrm{~g})
$$

This reaction leads to a decrease in the dielectric constant and, analogously to metallic iron atoms, a further increase of the loss factor. In addition, further reduction of the remaining iron oxides is expected to continue during this phase, increasing the number of Fe atoms. The corresponding increase in $\mathrm{CO}$ is observed (from generated $\mathrm{CO}_{2}$ and due to the Boudouard reaction) in the in-situ mass spectrometry during this stage.

Finally, stage 7 starts from $910^{\circ} \mathrm{C}$ with the vaporization of $\mathrm{Zn}$. This volatilization is also observed through the mass loss in the TG curve from this temperature, and it is associated to a decrease in the dielectric constant, whereas the loss factor remains constant. This effect on the dielectric constant matches with the observations made in [11]. The increasing temperatures affect the equilibrium of the Boudouard reaction leading to a gradual increase of the $\mathrm{CO}$ respect to the $\mathrm{CO}_{2}$ in the analyzed off-gas during this stage.

As a summary, Table 3 shows the main identified stages and reactions and their corresponding temperature ranges.

Table 3. Main identified stages during microwave carbothermic reduction.

\begin{tabular}{ccc}
\hline Stage & Temperature & Main Reactions \\
\hline 1 & $23{ }^{\circ} \mathrm{C}-330{ }^{\circ} \mathrm{C}$ & $\begin{array}{c}\text { Free water vaporization } \\
\text { Dehydration of Ca-Zn hydroxide hydrate } \\
\text { Dehydration of coke }\end{array}$ \\
\hline 3 & $330{ }^{\circ} \mathrm{C}-480{ }^{\circ} \mathrm{C}$ & $\begin{array}{c}\text { Dehydroxylation of calcium hydroxide } \\
\text { Decomposition of light components of coke }\end{array}$ \\
\hline 4 & $480{ }^{\circ} \mathrm{C}-590{ }^{\circ} \mathrm{C}$ & $\begin{array}{c}\text { Decomposition of zinc ferrite } \\
\text { Decomposition of magnetite to metallic iron } \\
\text { Decomposition of coke }\end{array}$ \\
\hline 5 & $590{ }^{\circ} \mathrm{C}-680^{\circ} \mathrm{C}$ & $\begin{array}{c}\text { Reduction of magnetite to wüstite } \\
\text { Boudouard reaction }\end{array}$ \\
\hline 7 & $680{ }^{\circ} \mathrm{C}-840{ }^{\circ} \mathrm{C}$ & $\begin{array}{c}\text { Wüstite reduction to metallic iron } \\
\text { Decomposition of calcium carbonate } \\
\text { Boudouard reaction }\end{array}$ \\
\hline 6 & $840{ }^{\circ} \mathrm{C}-910{ }^{\circ} \mathrm{C}$ & $\begin{array}{c}\text { Reduction of zinc oxide to zinc } \\
\text { Redion of remaining iron oxides to metallic iron } \\
\text { Boudouard reaction }\end{array}$ \\
\hline
\end{tabular}




\subsection{Dielectric Properties as a Function of Carbon Content}

Figure 4 shows the variation of dielectric properties of samples with different carbon to oxygen ratio $(\mathrm{C} / \mathrm{O})$ as a function of temperature under microwave heating. A constant heating rate of $15^{\circ} \mathrm{C} / \mathrm{min}$ was applied to all samples (see inset in Figure 4). The curves show the same behavior with increasing temperature indicating that the same reactions take place at the same temperatures. However, the magnitude of the dielectric properties differs between samples, evidencing that some reactions are enhanced by the presence of a higher carbon content.
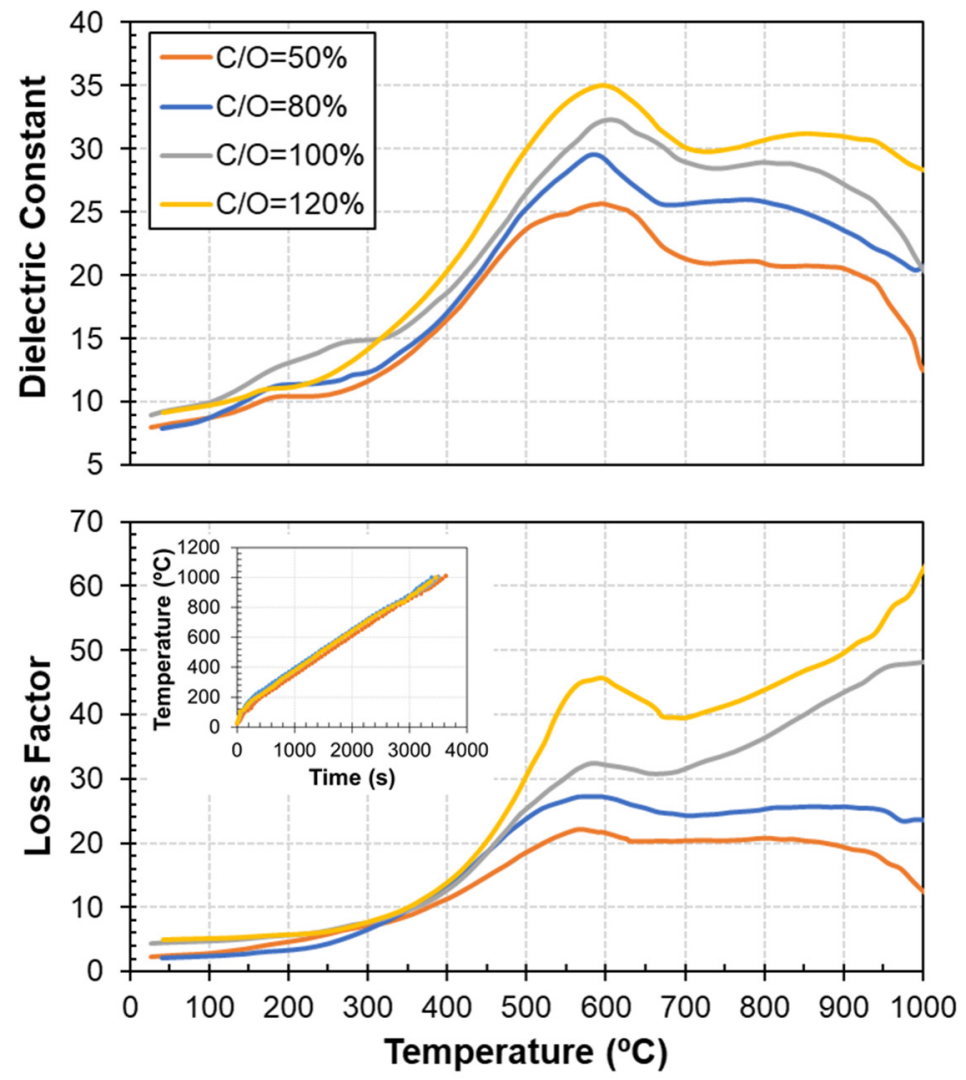

Figure 4. Dielectric properties of samples with different carbon content as a function of temperature.

Different opinions can be found in previous studies about which components are responsible for the good microwave absorbing properties of steelmaking residues. Some researchers state that loss factor is mainly influenced by the presence of carbonaceous material [7], whereas other studies emphasize that iron oxides are the main microwave absorbers [15], in particular magnetite over wüstite or hematite. These differences reflect the fact that many variables including the composition influence the loss factor that dictates the manner in which a material is heated by microwave energy. In the present study, loss factor during the first two stages is similar for different $\mathrm{C} / \mathrm{O}$ ratios, indicating that samples are excellent microwave absorbers with low dependence of carbon content, presumably because of the abundance of magnetite in the initial composition (see Table 2).

The differences in the dielectric properties become evident around $500{ }^{\circ} \mathrm{C}$ (stage 3), when the role of carbon gets significant as the zinc ferrite decomposition starts. At low $\mathrm{C} / \mathrm{O}$ ratios, the availability of carbon seems to be limiting the extent of reactions providing lower values of dielectric properties. Within the C/O ratios studied, the upper limit of excessive carbon (which would lead to undesirable formation of $\mathrm{Fe}_{3} \mathrm{C}$ ) has not been reached, since the dielectric properties still increase for the samples with higher $\mathrm{C} / \mathrm{O}$ ratio. Similar conclusions about the $\mathrm{C} / \mathrm{O}$ ratio were extracted in $[9,12]$ following different methodologies. Figure 4 suggests the possibility to use dielectric properties measurements to evaluate the optimum $\mathrm{C} / \mathrm{O}$ ratio without the need to perform additional analyses. 
Another remarkable difference is observed at high temperatures (stages 6 and 7) related to the reduction of zincite and volatilization of metallic zinc. For higher $\mathrm{C} / \mathrm{O}$ ratios, a larger amount of metallic zinc is produced. This means that more free charges become available and contribute to higher values of loss factor. The observed differences demonstrate a major role of electronic conduction in microwave heating at high temperatures, as suggested in [11].

Figure 5 shows the temperature dependence of the penetration depth for the different samples. The penetration depth is calculated from the measured dielectric properties and the operating frequency (close to $2.45 \mathrm{GHz}$ ) using Equation (2). It should be noted that penetration depth is sufficient with respect to the size of the sample (10 $\mathrm{mm}$ diameter, $15 \mathrm{~mm}$ height) to ensure a uniform electric field distribution inside the sample, avoiding big temperature gradients that could lead to different reaction stages taking place simultaneously inside the sample.

In all cases, penetration depth is reduced as temperature increases. This result is in agreement with observations made of similar materials by other researchers [15,25]. As expected, the penetration depth is higher in the case of lower carbon content due to lower loss factor values that allow deeper penetration of microwave energy into the sample. However, it is interesting to note that, as the temperature increases, the differences between samples decrease, reaching similar values (in the range from $1 \mathrm{~cm}$ to $2 \mathrm{~cm}$ ) at temperatures above $500{ }^{\circ} \mathrm{C}$. Thus, the effect of carbon content on the penetration depth is more noticeable at low temperatures, whereas the effect on the reaction enhancement is noticeable at high temperatures.

This decrease in the penetration depth at high temperatures requires careful consideration for scaling up the process. Efficient heating of the samples would be linked to a shallower penetration of the microwave energy, and the microwave applicator geometry and material feed profile should be adapted to maintain good efficiency and heating uniformity. Feasible industrial solutions would be parallel systems of appropriate size, or a continuous process system with a material layer thickness not much bigger than penetration depth values, for example, on a conveyor belt or in a microwave-transparent pipe. According to Equation (2), the use of a lower frequency such as $915 \mathrm{MHz}$ is expected to provide higher values of penetration depth [15]. However, a different microwave fixture would be needed for the measurement of material's dielectric properties at that frequency.

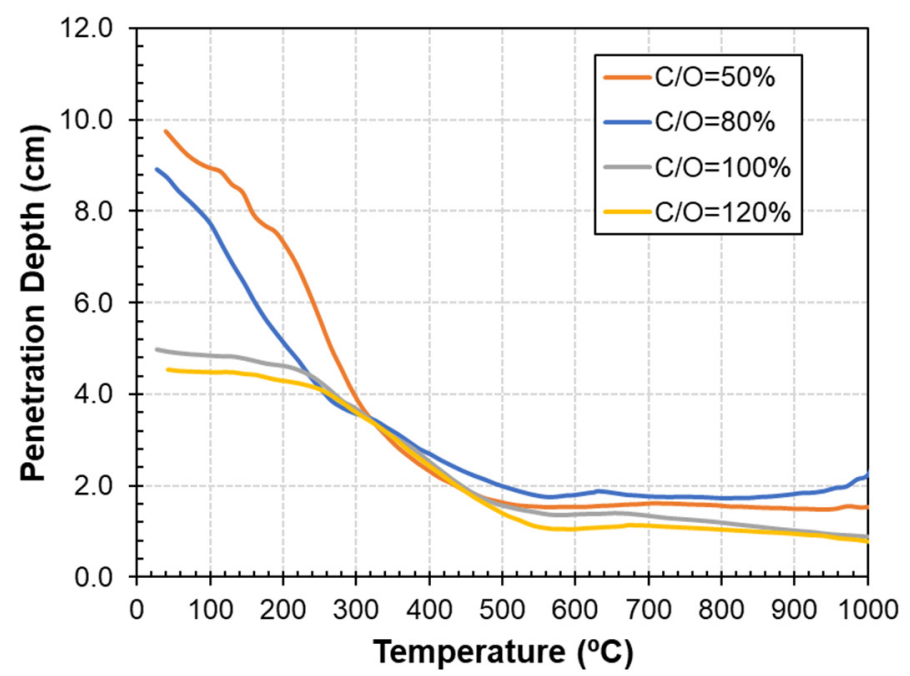

Figure 5. Penetration depth of samples with different carbon content as a function of temperature.

\subsection{Dielectric Properties as a Function of Compaction Density}

Figure 6 shows the dielectric properties of studied samples as a function of apparent density. Results show a notable variation of the dielectric properties for compaction densities ranging from approx. 0.9 to $1.65 \mathrm{~g} / \mathrm{mL}$. As expected, higher dielectric properties are observed for more compacted samples, since the amount of air is reduced in the mixture. Previous studies made on similar materials 
within narrow density ranges (i.e., from 1.54 to $1.63 \mathrm{~g} / \mathrm{mL}$ in [25]) concluded that temperature has a greater effect on dielectric properties than apparent density. The presented results show that, if a wide range of densities is considered, the effect on the dielectric properties can be comparable to the effect of temperature rise. These variations would be even bigger if samples are pelletized or briquetted for processing, as proposed in [10], and should be considered since they would affect key operation parameters such as the resulting penetration depth $[15,16]$.

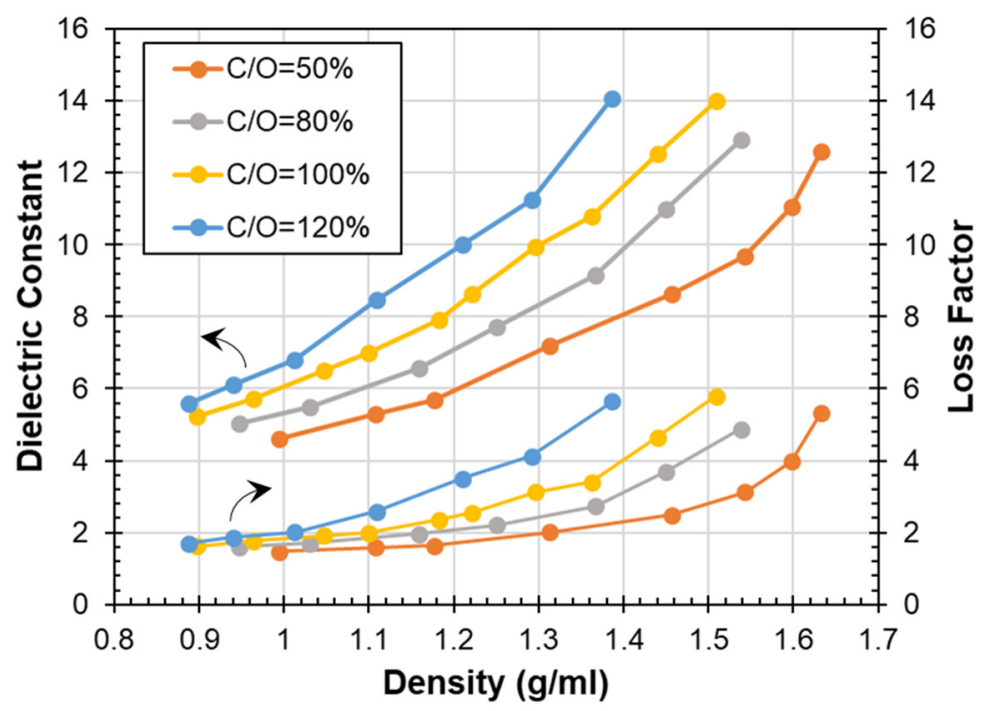

Figure 6. Dielectric properties of samples with different carbon content as a function of density.

\subsection{XRD Characterization}

Figure 7 shows the XRD patterns of the reference sample $(C / O=100 \%)$ before and after the process. In the raw mixture, the main iron- and zinc-bearing compounds are franklinite, hematite, and magnetite, with some wüstite. Quartz and calcite are also observed, whereas the presence of carbon can be clearly appreciated in the XRD pattern.

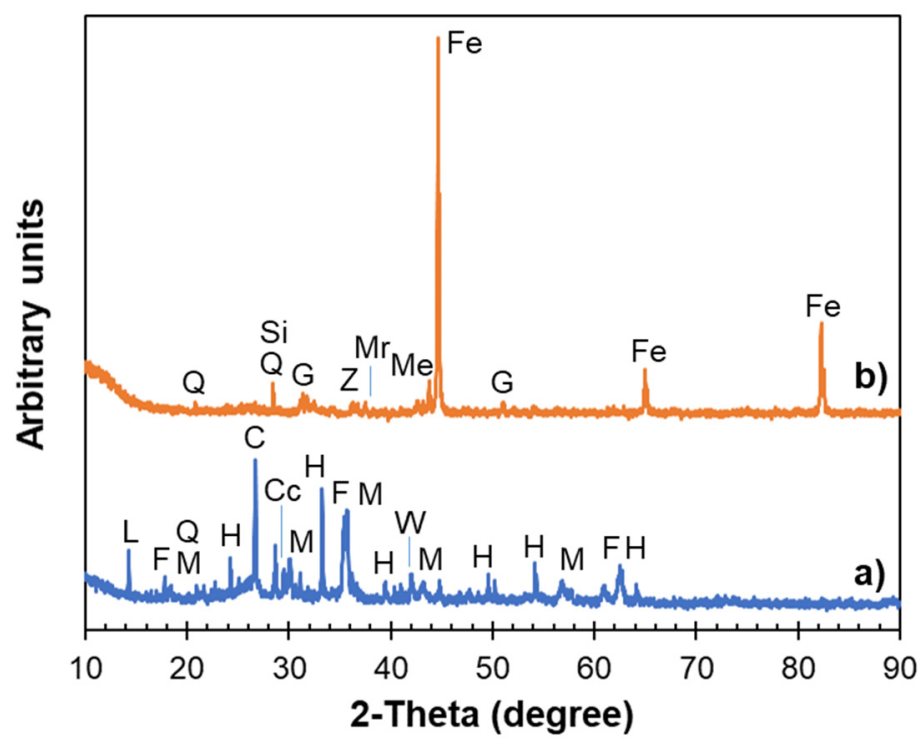

Figure 7. X-ray diffraction (XRD) pattern of reference sample $(C / O=100 \%)(a)$ before-see Table 2-and (b) after microwave treatment. $\mathrm{Q}=$ Quartz, $\mathrm{Si}=$ Silicon, $\mathrm{Cc}=$ Calcite, $\mathrm{G}=$ Gehlenite, $\mathrm{Z}=$ Zincite, $\mathrm{Mr}=$ Merwinite, $\mathrm{Me}=$ Melilite, $\mathrm{Fe}=$ Iron, $\mathrm{L}=$ Lepidocrocite, $\mathrm{F}=$ Franklinite, $\mathrm{M}=$ Magnetite, $\mathrm{H}=$ Hematite, $\mathrm{C}=$ Carbon (graphite), $\mathrm{W}=$ Wüstite. 
After the process, metallic iron appears as a result of the reduction of iron-bearing components. The pattern also reveals that there is no carbon left after the processes but a very small amount of zinc oxide remains after volatilization supporting the assumption that probably the carbon content in the reference sample is limiting the extent of expected reactions. A small presence of $\mathrm{Ca}, \mathrm{mg}, \mathrm{Si}$, and $\mathrm{Al}$ is observed in the form of gehlenite, melilite, and merwinite.

Pictures of the reference sample $(\mathrm{C} / \mathrm{O}=100 \%)$ before and after microwave treatment are presented in Figure 8. Sample mass before (1.63436 g) and after the process (1.37676 g) evidenced a mass loss $(15.7 \%)$ that matches the value given by the TG analysis (approx. $15 \%$ ) at $1000{ }^{\circ} \mathrm{C}$.

Zinc volatilization is verified through the observation of deposited zinc below the quartz frit, on the colder parts of the quartz holder. In particular, the zinc is observed as a ring on the tube at the zone surrounded by the cavity bottom wall, which is colder due to an integrated water-cooling system. This zone is outside the measuring chamber and therefore the deposited zinc does not affect the measurement accuracy. Figure 8 also shows the change in sample volume due to the sintering at high temperature.

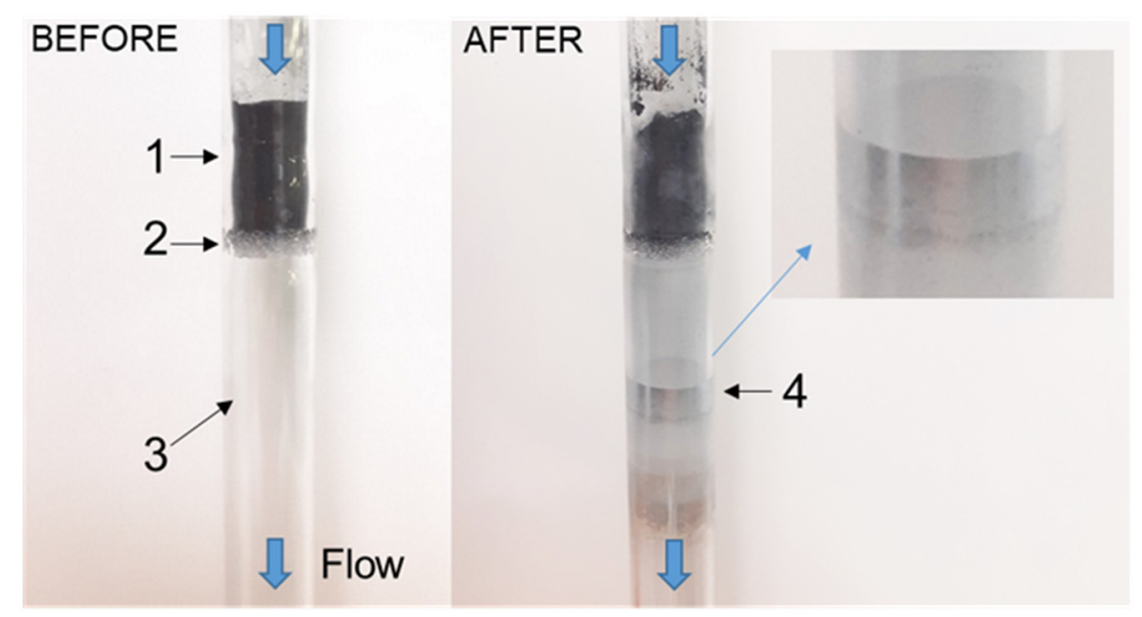

Figure 8. Reference sample before and after microwave treatment. (1) sample, (2) quartz frit to support the sample, (3) quartz holder, (4) volatilized zinc from the sample deposited on the quartz holder walls after treatment.

\section{Conclusions}

In-situ dielectric measurements, as demonstrated in this paper, allow comprehensive identification of all important stages during the carbothermic reduction of iron- and zinc- bearing products by microwave heating.

Results of dielectric properties during the reduction process agree very well with previous observations reported. Different techniques were used in this study compared to the work of other researchers and provided further details regarding the interaction of microwaves with this type of materials. Previous dielectric measurements provided information about up to three main stages $[11,13]$ due to the limitations imposed by the external heating procedures. The presented results with a combination of simultaneous microwave heating, dielectric monitoring, and mass spectrometry, could identify up to seven different stages during carbothermic reduction.

The identification of the main chemical and phase transformations during the microwave heating and their corresponding temperatures demonstrated the particularities of the microwave-driven heating mechanisms. The presented results suggested that molecular vibrations under microwave field increase the molecules activity, probably reducing the activation energy and leading to reactions taking place at lower temperatures. 
The effects of parameters such as the carbon content or the sample's apparent density were also evaluated and their impact on important microwave parameters (i.e., penetration depth) was determined, providing useful information for a potential microwave industrial application.

Recently developed advanced microwave systems open the possibility to study in a fast and convenient way the effect of different variables (composition, density, heating rate, atmosphere, etc.) and their impact on the dielectric properties, which govern the microwave process, improving our understanding of a promising microwave industrial application within the metallurgy field.

Author Contributions: Conceptualization, B.G.-B. and J.M.C.-C.; methodology, J.M.C.-C.; validation, B.G.-B., J.R.S., L.N., and A.M.L.-B.; formal analysis, B.G.-B., J.R.S., and L.N.; investigation, J.R.S., L.N., L.S., and A.M.L.-B.; resources, J.M.C.-C., A.M.L.-B., and L.S.; writing-original draft preparation, B.G.-B. and J.M.C.-C.; writing-review and editing, B.G.-B., J.M.C.-C., L.S., A.M.L.-B.; visualization, B.G.-B., A.M.L.-B.; supervision, J.M.C.-C. All authors have read and agreed to the published version of the manuscript.

Funding: This research was funded by the European Union's Horizon 2020 research and innovation programme under Grant Agreement number 820783.

Acknowledgments: The authors wish to thank Kersten Marx from VDEh-Betriebsforschungsinstitut GmbH and Carsten Hillmann from DK Recycling und Roheisen $\mathrm{GmbH}$ for providing the samples.

Conflicts of Interest: The authors declare no conflict of interest. The funders had no role in the design of the study; in the collection, analyses, or interpretation of data; in the writing of the manuscript, or in the decision to publish the results.

\section{References}

1. Agrawal, D. Microwave sintering of metal powders. In Advances in Powder Metallurgy; Chang, I., Zhao, Y., Eds.; Woodhead Publishing Limited: Cambridge, UK, 2013; pp. 361-379.

2. Veres, J.; Lovas, M.; Hredzak, S.; Zubrick, A.; Dolinska, S.; Skrinsky, J. Application of Microwave energy in waste treatment. J. Pol. Min. Eng. Soc. 2017, 1, 39-44.

3. Panias, D.; Krestou, A. Use of microwave energy in metallurgy. In Proceedings of the 1st International Conference on Advances in Mineral Resources Management and Environmental Geotechnology, AMIREG, Hania, Greece, 7-9 June 2004; pp. 215-220.

4. World Steel Association. Steel Statistical Yearbook 2019; World Steel Association: Brussels, Belgium, 2019.

5. Omran, M.; Fabritius, T.; Mattila, R. Thermally assisted liberation of high phosphorus oolitic iron ore: A comparison between microwave and conventional furnaces. Powder Technol. 2015, 269, 7-14. [CrossRef]

6. Omran, M.; Fabritius, T.; Heikkinen, E.; Chen, G. Dielectric properties and carbothermic reduction of zinc oxide and zinc ferrite by microwave heating. R. Soc. Open Sci. 2017, 4, 170710. [CrossRef] [PubMed]

7. Mourão, M.B.; Carvalho, I.P.; Takano, C. Carbothermic reduction by microwave heating. ISIJ Int. 2001, 41, S27-S30. [CrossRef]

8. Standish, N.; Huang, W. Microwave application in carbothermic reduction of iron ores. ISIJ Int. 1991, 3, 241-245. [CrossRef]

9. Wang, X.; Yang, D.; Ju, S.; Peng, J.; Duan, X. Thermodynamics and kinetics of carbothermal reduction of zinc ferrite by microwave heating. Trans. Nonferrous Met. Soc. China 2013, 23, 3808-3815. [CrossRef]

10. Quing, Y.; Guanghui, L.; Zhiwei, P.; Joonho, L.; Xiaolong, L.; Mingjun, R.; Yuanbo, Z.; Tao, J. Microwave-assisted self-reduction of composite briquettes of zinc ferrite and carbonaceous materials. Powder Technol. 2019, 342, 224-232.

11. Quing, Y.; Zhiwei, P.; Guanghui, L.; Joonho, L.; Yong, L.; Mundan, L.; Liancheng, W.; Mingjun, R.; Yuanbo, Z.; Tao, J. Microwave-assisted reduction of electric arc furnace dust with biochar: An examination of transition of heating mechanism. ACS Sustain. Chem. Eng. 2019, 7, 9515-9524.

12. Quing, Y.; Guanghui, L.; Zhiwei, P.; Augustine, R.; Perez, M.D.; Yong, L.; Mudan, L.; Mingjun, R.; Yuanbo, Z.; Tao, J. Microwave-assisted self-reduction of EAF dust-biochar composite briquettes for production of direct reduced iron. Powder Technol. 2020, 362, 781-789.

13. Ishizaki, K.; Nagata, K.; Hayashi, T. Production of pig iron from magnetite ore-coal composite pellets by microwave heating. ISIJ Int. 2006, 46, 1403-1409. [CrossRef] 
14. Liu, C.; Zhang, L.; Peng, J.; Liu, B.; Xia, H.; Gu, X.; Shi, Y. Effect of temperature on dielectric property and microwave heating behaviour of low grade Panzhihua ilmenite ore. Trans. Nonferrous Met. Soc. China 2013, 23, 3462-3469. [CrossRef]

15. Omran, M.; Fabritius, T.; Guo, C.; Aoxi, H. Microwave absorption properties of steelmaking dusts: Effects of temperature on the dielectric constant and loss factor at $1064 \mathrm{MHz}$ and $2423 \mathrm{MHz}$. RSC Adv. 2019, 9, 6859-6870. [CrossRef]

16. Zhang, L.; Ma, A.; Liu, C.; Qu, W.; Peng, J.; Luo, Y.; Zuo, Y. Dielectric properties and temperature increase characteristics of zinc oxide dust from fuming furnace. Trans. Nonferrous Met. Soc. China 2014, 24, 4004-4011. [CrossRef]

17. Al-harahsheh, M.; Kingman, S.; Al-Makhadmah, L.; Hamilton, I.E. Microwave treatment of electric furnace dust with PVC: Dielectric characterization and pyrolysis-leaching. J. Hazard Mater. 2014, 274, 87-89. [CrossRef] [PubMed]

18. Clarke, R.N.; Gregory, A.P.; Cannell, D.; Patrick, M.; Wylie, S.; Youngs, I.; Hill, G. A Guide to the Characterisation of Dielectric Materials at RF and Microwave Frequencies; Technical Report; Institute of Measurement and Control, National Physical Laboratory: London, UK, 2003; pp. 115-123.

19. García-Baños, B.; Catalá-Civera, J.M.; Peñaranda-Foix, F.; Plaza-González, P.; Llorens-Valles, G. In Situ Monitoring of Microwave Processing of Materials at High Temperatures through Dielectric Properties Measurement. Materials 2016, 9, 349. [CrossRef]

20. García-Baños, B.; Reinosa, J.J.; Peñaranda-Foix, F.; Fernández, J.F.; Catalá-Civera, J.M. Temperature assessment of microwave-enhanced heating processes. Sci. Rep. 2019, 9, 10809. [CrossRef]

21. Catalá-Civera, J.M.; Canós-Marín, A.J.; Plaza-González, P.; Gutiérrez-Cano, J.D.; García-Baños, B.; Peñaranda-Foix, F. Dynamic Measurement of Dielectric Properties of Materials at High Temperature During Microwave Heating in a Dual Mode Cylindrical Cavity. IEEE Trans. Microw. Theory Technol. 2015, 63, 2905-2914. [CrossRef]

22. Gutiérrez-Cano, J.D.; Plaza-González, P.; Canós-Marín, A.J.; García-Baños, B.; Catalá-Civera, J.M.; Peñaranda-Foix, F. A new standalone microwave instrument for measuring the complex permittivity of materials at microwave frequencies. IEEE Trans. Instrum. Meas. 2019, 69, 3595-3605. [CrossRef]

23. Yucel, O.; Demirci, F.; Turan, A.; Alkan, M. Determination of direct reduction conditions of mil scale. High Temp. Mater. Process. 2013, 32, 405-412. [CrossRef]

24. Zhu-Cheng, H.; Kai, W.; Bing, H.; Peng, H.; Tao, J. Non-Isothermal Kinetics of Reduction Reaction of Oxidized Pellet under Microwave Irradiation. J. Iron Steel Res. Int. 2012, 19, 1-4.

25. He, G.; Li, S.; Yang, K.; Liu, J.; Liu, P.; Zhang, L.; Peng, J. Dielectric properties of zinc sulphide concentrate during the roasting at microwave frequencies. Minerals 2017, 7, 31. [CrossRef] 